\title{
The most influential papers in unicompartmental knee arthroplasty
}

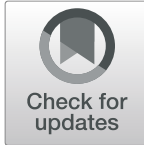

Lukas A. Holzer ${ }^{1 *}$ and Gerold Holzer ${ }^{2}$

\begin{abstract}
Purpose: Unicompartmental knee arthroplasty (UKA) is a treatment option for anteromedial osteoarthritis of the knee. The number of UKA has been increasing constantly worldwide in recent decades. The aim of this study was to determine the most frequently cited scientific articles addressing this subject and to establish a ranking of the 50 most influential papers.

Methods: The 50 most cited articles related to UKA were searched in Web of Science ${ }^{\circledast}$ (Clarivate Analytics, Penn., USA) by the use of defined search terms. All types of scientific papers with reference to this topic were ranked according to the absolute number of citations and analyzed for the following characteristics: journal title, year of publication, number of citations, citation density, geographic origin, article type, and level of evidence.

Results: The 50 most cited articles had up to 453 citations. Most papers were published in the Journal of Bone and Joint Surgen (British volume). More than half of the articles were published in the 2000s and 2010s $(n=30)$. Ten countries contributed to the top 50 list, with most contributions from the UK $(n=17)$. Most articles could be attributed to the category of Clinical Science $(n=33)$, and most reported level IV studies.

Conclusion: Most of the frequently cited articles in UKA are clinical studies that have a low level of evidence. Few basic scientific studies could be identified, which suggests that most product development is done by commercial companies.
\end{abstract}

Keywords: Unicompartmental knee arthroplasty, Unicondylar knee arthroplasty, Bibliometric study, Citation analysis

\section{Introduction}

Unicompartmental knee arthroplasty (UKA) dates back to the 1950s, following the introduction of the MacIntosh and McKeever hemiarthroplasty [1]. Since then, patient management, implant design, and surgical techniques, such as patient-specific instrumentation, have advanced [1, 2]. Nowadays, UKA is considered a less-invasive treatment option for anteromedial osteoarthritis than total knee (TKA) arthroplasty [3-5]. As a result, the number of UKA has been increasing constantly worldwide in recent decades [68]. Due to the clinical relevance of UKA, numerous scientific papers related to this topic were published, that is, more than 2000 articles.

\footnotetext{
* Correspondence: lukas.holzer@auva.at

'Department of Orthopedic Surgery, AUVA Trauma Center Klagenfurt, Waidmannsdorferstraße 35, 9020 Klagenfurt am Wörthersee, Austria Full list of author information is available at the end of the article
}

A citation is a reference or a quotation from previous scientific work that has been published in books or scientific journals [9]. The number of citations of published scientific articles is considered a parameter of its influence and impact in the scientific community. The impact factor of a journal is a widely accepted as a parameter of scientific quality and importance. It is calculated by the number of citations [9].

Analyses of citations in a specific scientific field allow us to give an overview of the most influential articles and offer physicians, researchers, and residents insight on the relevant current literature. Such studies have been done in different medical disciplines such as orthopedic surgery or general surgery; in a variety of orthopedic subspecialties including arthroplasty, arthroscopy, or hand surgery; and for conditions such as osteoporosis or anterior cruciate ligament rupture [10-21].

The aim of this study was to determine the most cited scientific articles related to UKA and to establish a

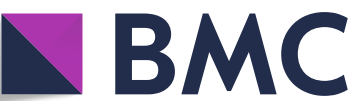

Part of Springer Nature (c) The Author(s). 2020 Open Access This article is licensed under a Creative Commons Attribution 4.0 International License, which permits use, sharing, adaptation, distribution and reproduction in any medium or format, as long as you give appropriate credit to the original author(s) and the source, provide a link to the Creative Commons licence, and indicate if changes were made. The images or other third party material in this article are included in the article's Creative Commons licence, unless indicated otherwise in a credit line to the material. If material is not included in the article's Creative Commons licence and your intended use is not permitted by statutory regulation or exceeds the permitted use, you will need to obtain permission directly from the copyright holder. To view a copy of this licence, visit http://creativecommons.org/licenses/by/4.0/. The Creative Commons Public Domain Dedication waiver (http://creativecommons.org/publicdomain/zero/1.0/) applies to the data made available in this article, unless otherwise stated in a credit line to the data. 


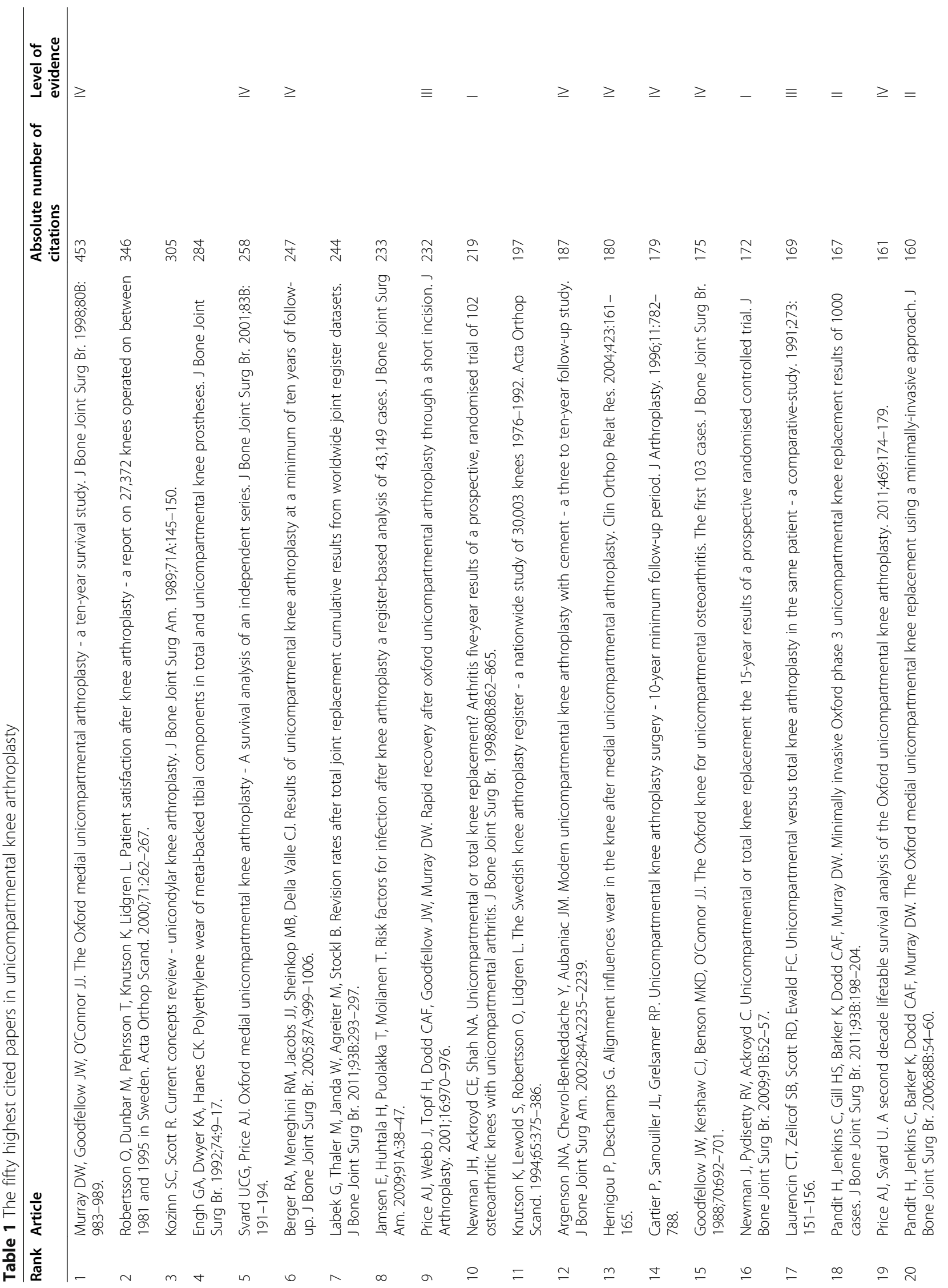




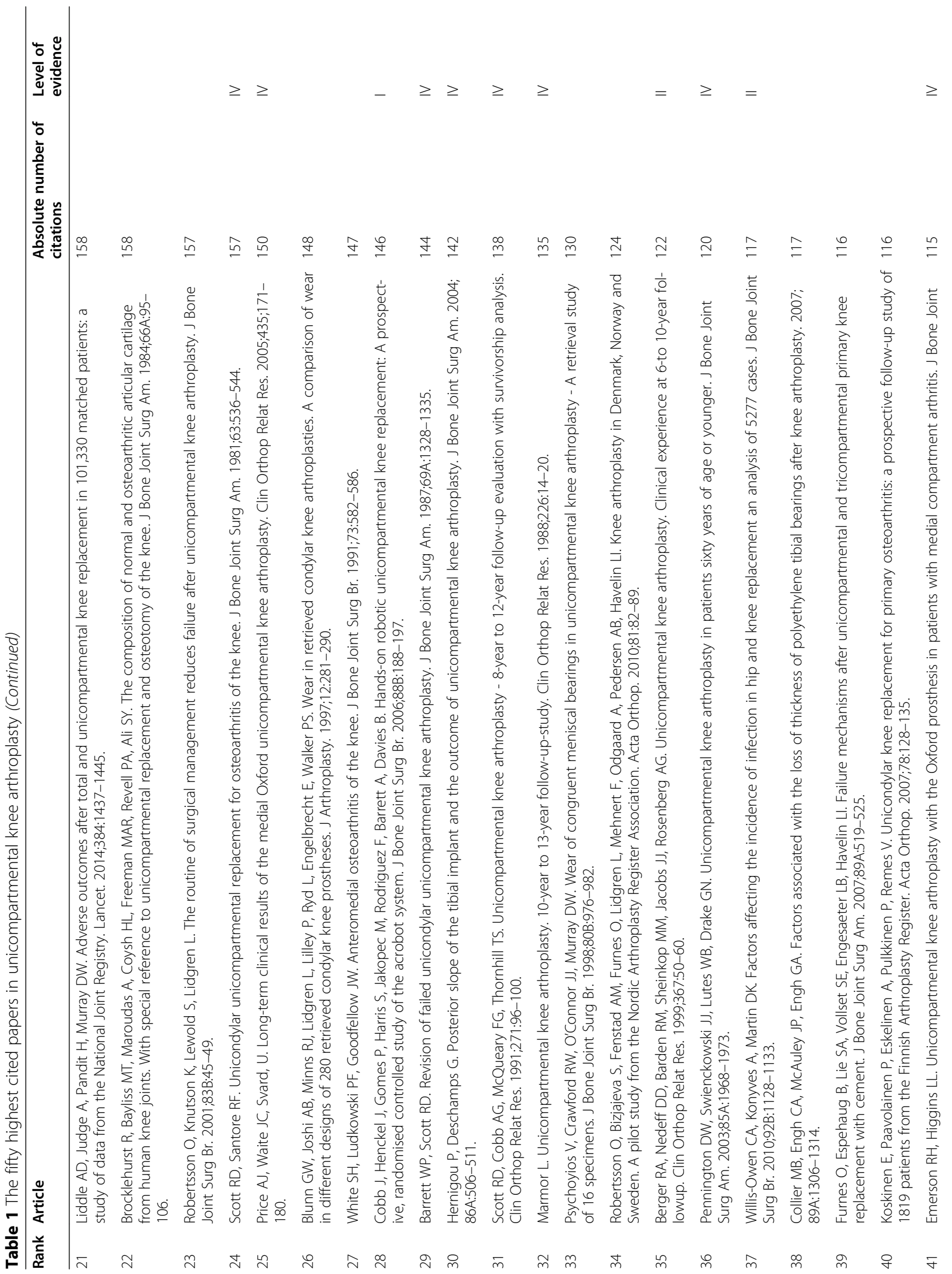




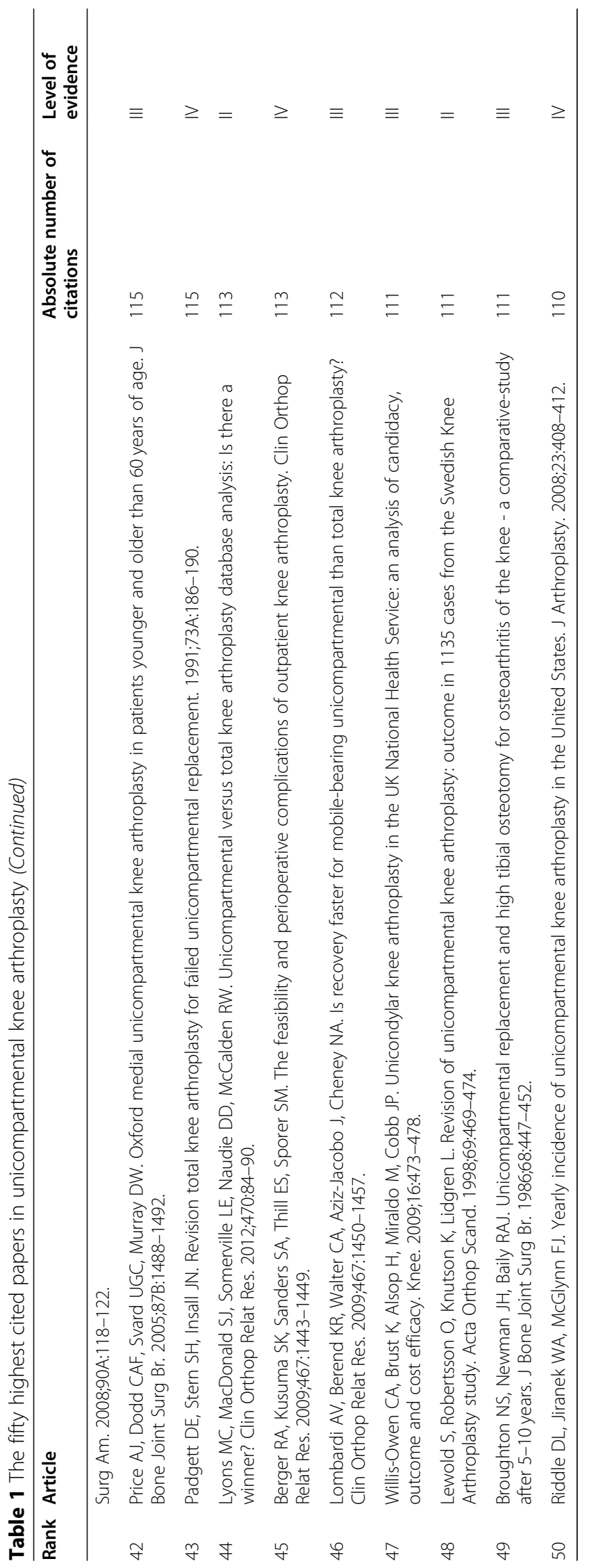


ranking of the most influential papers by the use of the Web of Science ${ }^{\circ}$ database.

\section{Material and methods Search strategy}

In March 2020, Web of Science (Clarivate Analytics, Penn., USA) was searched for the following search terms "Unicompartmental Knee Arthroplasty," "Unicondylar Knee Arthroplasty," "Unicompartmental Knee Replacement," "Knee Arthroplasty," "Knee Replacement," "Implant," and "Prosthesis."

The search output was documented after completion of the search. All scientific articles related to UKA that could be identified were included and ranked according to the absolute number of citations (times cited in the Web of Science core collection). If the absolute number of citations was the same in two or more papers, the publication that had the higher citation density (see below) was ranked higher. The fifty most cited articles were chosen and represent the list of the most influential papers in UKA. The literature search and subsequent data analysis were done by a board-certified orthopedic surgeon.

\section{Data analysis}

The fifty most cited articles were studied in detail for the following characteristics: article title, journal title, year of publication, and origin of the corresponding author. Each publication was assigned to a single country of origin. This decision was based on the corresponding author's address, as the corresponding author is in charge of the article and the guarantor of the data [22].

A citation density (the number of citations per year since publication) was calculated to show the relative impact of the included articles [17].

The included articles were allocated to different scientific categories as follows: "Clinical Science," "Basic Science," "Registry \& Database," and "Review."

The level of evidence was assessed in all articles that were attributed to the Clinical Science category. This assessment was done according to the guidelines for clinical articles by the Oxford Centre for Evidence-Based Medicine 2016 Levels of Evidence [23].

\section{Results}

The absolute number of citations for the fifty most cited articles on UKA range from 110 to 453 times. The fifty articles were cited, in total, 8436 times. The mean number of citations of an included paper was 169 times $( \pm 69)$. The top ten papers reached at least 219 citations since publication.

The absolute numbers of citations for the fifty most influential articles on UKA are shown in Table 1, and the top ten papers, according to their relative number of citations (highest citation density), are presented in Table 2.

Thirty-three articles were allocated to the "Clinical Science" category, which was the most frequently noted category. Figure 1 presents the distribution according to the different categories.Within the category "Clinical Science," the level of evidence was analyzed. Eighteen studies of this category were categorized as level IV studies.

Table 2 The ten highest cited papers in unicompartmental knee arthroplasty in relative numbers

\begin{tabular}{|c|c|c|c|}
\hline Rank & Article & $\begin{array}{l}\text { Citation } \\
\text { density }\end{array}$ & $\begin{array}{l}\text { Level of } \\
\text { evidence }\end{array}$ \\
\hline 1 & $\begin{array}{l}\text { Labek G, Thaler M, Janda W, Agreiter M, Stockl B. Revision rates after total joint replacement cumulative results } \\
\text { from worldwide joint register datasets. J Bone Joint Surg Br. 2011;93B:293-297. }\end{array}$ & 27,11 & \\
\hline 2 & $\begin{array}{l}\text { Liddle AD, Judge A, Pandit H, Murray DW. Adverse outcomes after total and unicompartmental knee } \\
\text { replacement in 101,330 matched patients: a study of data from the National Joint Registry. Lancet. 2014;384: } \\
\text { 1437-1445. }\end{array}$ & 26,33 & \\
\hline 3 & $\begin{array}{l}\text { Jamsen E, Huhtala H, Puolakka T, Moilanen T. Risk factors for infection after knee arthroplasty a register-based } \\
\text { analysis of 43,149 cases. J Bone Joint Surg Am. 2009;91A:38-47. }\end{array}$ & 21,18 & \\
\hline 4 & $\begin{array}{l}\text { Murray DW, Goodfellow JW, O'Connor JJ. The Oxford medial unicompartmental arthroplasty - a ten-year survival } \\
\text { study. J Bone Joint Surg Br. 1998;80B:983-989. }\end{array}$ & 20,59 & IV \\
\hline 5 & $\begin{array}{l}\text { Pandit H, Jenkins C, Gill HS, Barker K, Dodd CAF, Murray DW. Minimally invasive Oxford phase 3 } \\
\text { unicompartmental knee replacement results of } 1000 \text { cases. J Bone Joint Surg Br. 2011;93B:198-204. }\end{array}$ & 18,56 & ॥ \\
\hline 6 & $\begin{array}{l}\text { Price AJ, Svard U. A second decade lifetable survival analysis of the Oxford unicompartmental knee arthroplasty. } \\
2011 ; 469: 174-179 \text {. }\end{array}$ & 17,89 & IV \\
\hline 7 & $\begin{array}{l}\text { Robertsson O, Dunbar M, Pehrsson T, Knutson K, Lidgren L. Patient satisfaction after knee arthroplasty - a report } \\
\text { on 27,372 knees operated on between } 1981 \text { and } 1995 \text { in Sweden. Acta Orthop Scand. 2000;71:262-267. }\end{array}$ & 17,3 & \\
\hline 8 & $\begin{array}{l}\text { Berger RA, Meneghini RM, Jacobs JJ, Sheinkop MB, Della Valle CJ. Results of unicompartmental knee arthroplasty } \\
\text { at a minimum of ten years of follow-up. J Bone Joint Surg Br. 2005;87A:999-1006. }\end{array}$ & 16,47 & IV \\
\hline 9 & $\begin{array}{l}\text { Newman J, Pydisetty RV, Ackroyd C. Unicompartmental or total knee replacement the 15-year results of a pro- } \\
\text { spective randomised controlled trial. J Bone Joint Surg Br. 2009;91B:52-57. }\end{array}$ & 15,63 & I \\
\hline 10 & $\begin{array}{l}\text { Lyons MC, MacDonald SJ, Somerville LE, Naudie DD, McCalden RW. Unicompartmental versus total knee } \\
\text { arthroplasty database analysis: Is there a winner? Clin Orthop Relat Res. 2012;470:84-90. }\end{array}$ & 14,13 & $\|$ \\
\hline
\end{tabular}




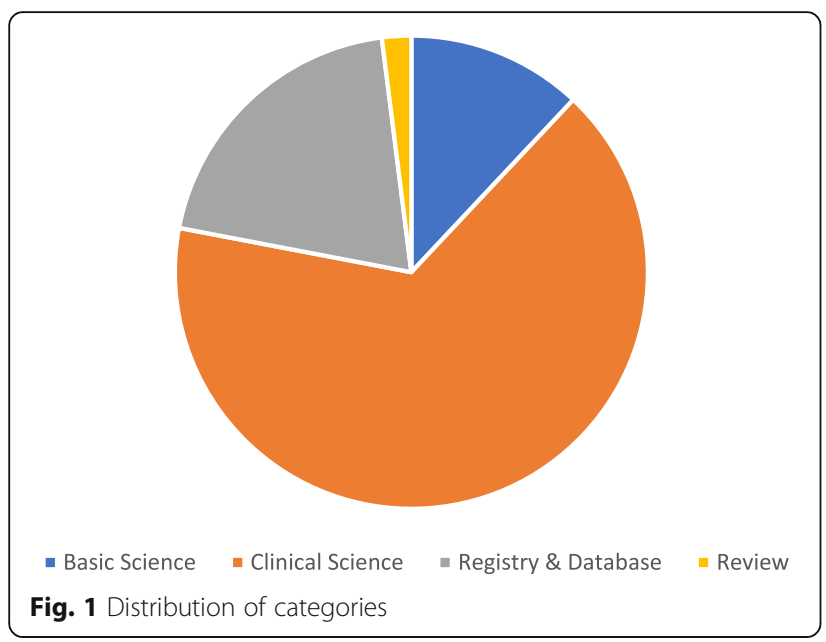

The distribution of the level of evidence is shown in Fig. 2.

The Journal of Bone and Joint Surgery (British volume) has published most papers of the list $(n=16)$. The Journal of Bone and Joint Surgery (American volume), Clinical Orthopaedics and Related Research, Acta Orthopaedica (Scandinavica), Journal of Arthroplasty, Lancet, and Knee were other journals that contributed to the list (Fig. 3).

Research institutions from the UK had the highest number of contributions $(n=17)$. Nine further countries contributed to the top 50 list: the USA with 16; Sweden with six; France with four; Finland with two; and Australia, Austria, Canada, India, and Norway with one each. Thirty-one publications were from Europe and 17 from North America.
The publication years of these articles span 1981 to 2014. Figure 4 shows the decade in which the research was published. Most articles were published in the 2000s $(n=23)$, followed by the 1990s $(n=$ 13 ), and then the 1980s and 2010s with seven publications per decade.

\section{Discussion}

UKA is considered an alternative treatment option for anteromedial osteoarthritis to TKA. Because of the growing scientific interest in the field of UKA, we tried to identify the most influential articles related to UKA as guidance for clinical practice and future research. Publications on UKA were cited up to 453 times since publication, with the top ten articles in this field being cited at least 219 times. The citation number of articles in UKA is lower than in other fields of orthopedics, such as total hip and knee arthroplasty, cartilage surgery, and anterior cruciate ligament injury [13, 16, 20, 21]. However, compared to articles on hand surgery or pediatric orthopedics, articles on UKA are well cited $[15,18]$. This indicates that the field of UKA is a highly driven industry such as the field of arthroplasty on the whole [24, 25].More than two-thirds of the articles were attributed to the category "Clinical Science." Most of these were level IV studies, which indicates a low level of evidence in the field of UKA. This points to a need for clinical studies in UKA with better study design so as to gain more evidence in the future. Only three articles were level I studies. Two of these were prospective randomized controlled trials comparing UKA and TKA in the treatment of osteoarthritis of the knee.

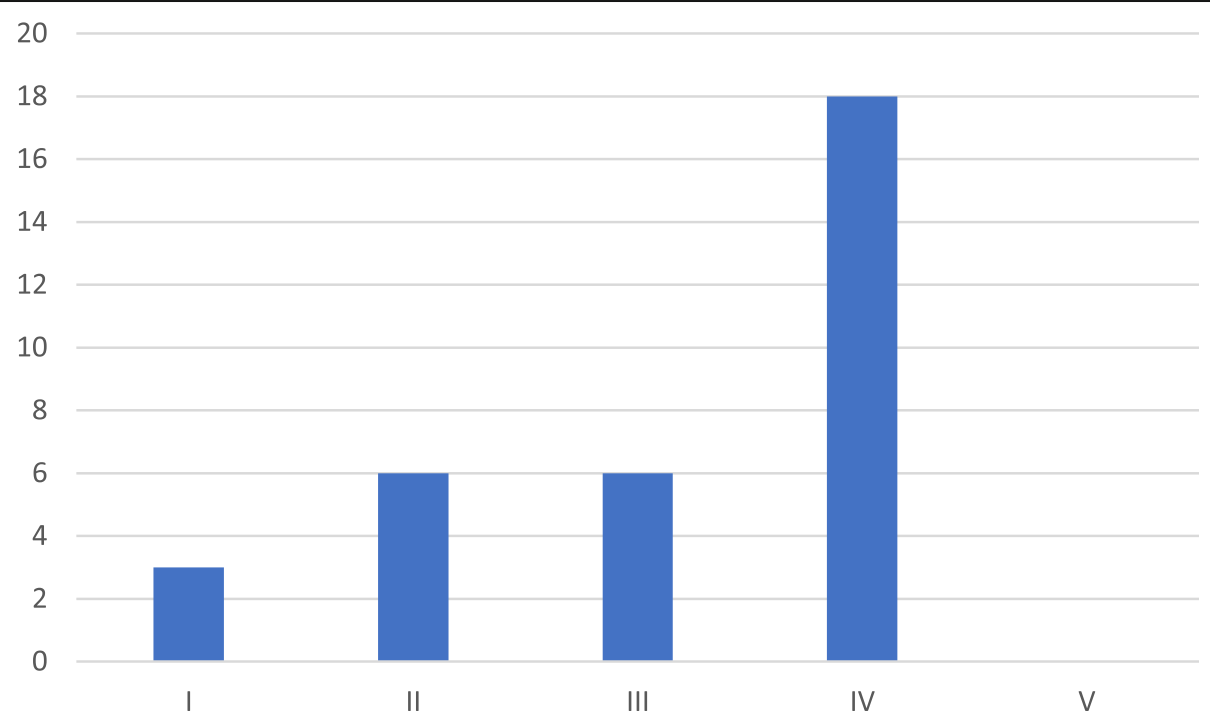

Fig. 2 Distribution of the level of evidence in the clinical studies 


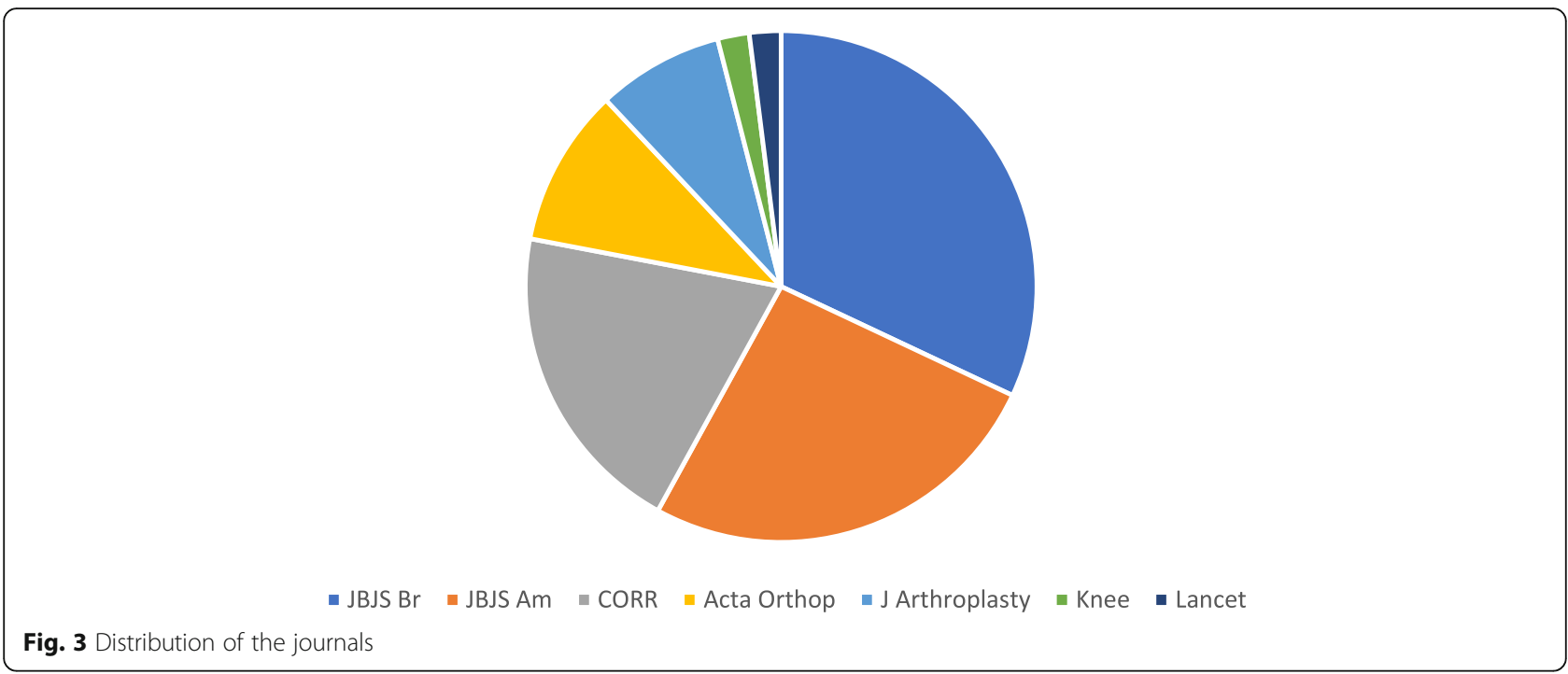

The second most frequent category was "Registry and Database," with ten articles. This indicates the great interest in implant performance and survival. Only six papers were in the category "Basic Science." Product developments in the field of UKA are mostly done by commercial companies. These products are then used in clinical practice and studied clinically. Interestingly, the most highly cited contributions in the field of UKA were from the UK $(n=17)$. This is in contrast to most bibliometric analyses done so far, in which the USA contributed most of the scientific work [10-21]. Furthermore, in the field of UKA, a high number of contributions are from European countries, especially Scandinavian ones. This is also confirmed by the publishing journals. A large proportion of the articles was published in the Journal of Bone and Joint Surgery (British volume). Another seven articles were published in European journals. This finding is also in contrast to other bibliometric analyses in orthopedic surgery so far [10-21]. Interestingly, most articles have been published since 2000. This indicates an increasing trend in UKA in the last recent decades.

In general, bibliometrics has its limitations. The identification of the fifty most cited papers still remains a selection, even when using predefined search criteria. In this study, the absolute number of citations was considered an objective parameter. Among the scientific community, the impact factor is an accepted parameter of an article's influence. The impact factor is directly influenced by the number of citations. However, the citation numbers of articles can be manipulated by various factors such as self-citations (in small numbers) and therefore might not necessarily represent the objective value of scientific work [9].

The literature search was performed in the Web of Science ${ }^{\circ}$. Textbooks, doctoral theses, presentations, and new media are not included in this database. Therefore,

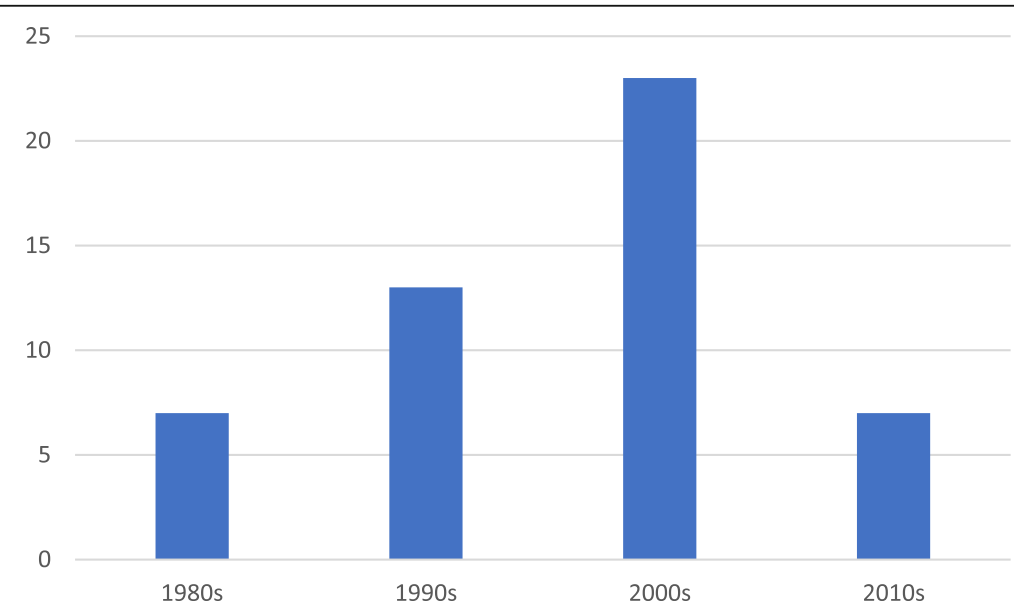

Fig. 4 Distribution of articles according to publication decades 
citations of articles of such sources might have been missed.

Another limiting factor might be the cross-sectional study design based on total citation numbers. As a result, more recent influential papers might not have been identified and were not considered eligible for the list.

\section{Conclusions}

This study provides a list of the fifty most influential articles on UKA, which will help physicians and scientists to obtain an overview on past and current trends in the field of UKA. Most articles could be attributed to the category Clinical Science and provided a low level of evidence. This provides a basis for both further discussion and highlights the need for future research.

\section{Acknowledgements}

Not applicable.

\section{Authors' contributions}

$\mathrm{LAH}$ designed the study, collected and analyzed the data, wrote the initial manuscript draft, and read and approved the final version of the manuscript. $\mathrm{GH}$ designed the study, analyzed the data, and read and approved the final version of the manuscript. All authors read and approved the final manuscript.

\section{Funding}

This research did not receive any specific grant from funding agencies in the public, commercial, or not-for-profit sectors.

\section{Availability of data and materials}

The datasets developed during and/or analyzed during the current study are available from the corresponding author on reasonable request.

\section{Ethics approval and consent to participate}

Not applicable.

\section{Consent for publication}

Not applicable.

\section{Competing interests}

The authors declare that they have no competing interests.

\section{Author details}

${ }^{1}$ Department of Orthopedic Surgery, AUVA Trauma Center Klagenfurt, Waidmannsdorferstraße 35, 9020 Klagenfurt am Wörthersee, Austria.

${ }^{2}$ Department of Orthopedics and Traumatology, Medical University of Vienna, Vienna, Austria.

Received: 24 July 2020 Accepted: 22 September 2020 Published online: 09 October 2020

\section{References}

1. Johal S, Nakano N, Baxter M, Hujazi I, Pandit H, Khanduja V (2018) Unicompartmental knee arthroplasty: the past, current controversies, and future perspectives. J Knee Surg 31:992-998

2. Vince KG, Cyran LT (2004) Unicompartmental knee arthroplasty: new indications, more complications? J Arthroplast 19:9-16

3. Jennings JM, Kleeman-Forsthuber LT, Bolognesi MP (2019) Medial unicompartmental arthroplasty of the knee. J Am Acad Orthop Surg 27: 166-176

4. Murray DW, Parkinson RW (2018) Usage of unicompartmental knee arthroplasty. Bone Joint J 100-B:432-435
5. Christ AB, Pearle AD, Mayman DJ, Haas SB (2018) Robotic-assisted unicompartmental knee arthroplasty: state-of-the art and review of the literature. J Arthroplast 33:1994-2001

6. Riddle DL, Jiranek WA, McGlynn FJ (2008) Yearly incidence of unicompartmental knee arthroplasty in the United States. J Arthroplast. 23 408-412

7. Kahlenberg CA, Richardson SS, Gruskay JA, Cross MB (2020) Trends in utilization of total and unicompartmental knee arthroplasty in the United States. J Knee Surg. https://doi.org/10.1055/s-0040-1702189

8. Hansen EN, Ong KL, Lau E, Kurtz SM, Lonner JH (2018) Unicondylar knee arthroplasty in the U.S. patient population: prevalence and epidemiology. Am J Orthop (Belle Mead NJ) 47. https://doi.org/10.12788/ajo.2018.0113

9. Lee KP, Schotland M, Bacchetti P, Bero LA (2002) Association of journal quality indicators with methodological quality of clinical research articles. JAMA 287:2805-2808

10. Kelly JC, Glynn RW, O'Briain DE, Felle P, McCabe JP (2010) The 100 classic papers of orthopaedic surgery: a bibliometric analysis. J Bone Joint Surg $\mathrm{Br}$ 92:1338-1343

11. Lefaivre KA, Shadgan B, O'Brien PJ (2011) 100 most cited articles in orthopaedic surgery. Clin Orthop Relat Res 469:1487-1497

12. Paladugu R, Schein M, Gardezi S, Wise L (2002) One hundred citation classics in general surgical journals. World J Surg 26:1099-1105

13. Holzer LA, Holzer G (2014) The 50 highest cited papers in hip and knee arthroplasty. J Arthroplast 289:453-457

14. Cassar Gheiti AJ, Downey RE, Byrne DP, Molony DC, Mulhall KJ (2012) The 25 most cited articles in arthroscopic orthopaedic surgery. Arthroscopy 28 : 548-564

15. To P, Atkinson CT, Lee DH, Pappas ND (2013) The most cited articles in hand surgery over the past 20-plus years: a modern-day reading list. J Hand Surg 38A:983-987

16. Arshi A, Siesener NJ, McAllister DR, Williams R 3rd, Sherman SL, Jones KJ (2016) The 50 most cited articles in orthopedic cartilage surgery. Cartilage 7: 238-247

17. Namdari S, Baldwin K, Kovatch K, Huffman GR, Glaser D (2012) Fifty most cited articles in orthopaedic shoulder surgery. J Shoulder Elb Surg 21:17961802

18. Kavanagh RG, Kelly JC, Kelly PM, Moore DP (2013) The 100 classic papers of pediatric orthopaedic surgery: a bibliometric analysis. J Bone Joint Surg Am 95:e134

19. Holzer LA, Leithner A, Holzer G (2015) The most cited papers in osteoporosis and related research. J Osteoporos 2015:638934

20. Vielgut I, Dauwe J, Leithner A, Holzer LA (2017) The fifty highest cited papers in anterior cruciate ligament injury. Int Orthop 41:1405-1412

21. Ennis HE, Bondar K, McCormick J, Chen CJ, Donnally CJ 3rd, Kaplan L (2020) The 50 most cited articles in the indications, risk factors, techniques, and outcomes of ACL revision surgery. J Knee Surg. https://doi.org/10.1055/s0040-1702182

22. Rennie D, Flanagin A, Yank V (2002) The contributions of authors. JAMA 284: 89-91

23. OCEBM Levels of Evidence Working Group. "The Oxford levels of evidence 2". Oxford Centre for Evidence-Based Medicine. https://www.cebm.net/2 016/05/ocebm-levels-of-evidence. Accessed 28 Mar 2020.

24. Holzer LA, Holzer G (2013) Analysis of scientific articles published in two general orthopaedic journals. Acta Ortop Bras 21:281-284

25. Boddapati V, Sachdev R, Fu MC, Camp CL, Marx RG, Dines JS (2018) Increasing industry support is associated with higher research productivity in orthopaedic surgery. J Bone Joint Surg Am 100:e36

\section{Publisher's Note}

Springer Nature remains neutral with regard to jurisdictional claims in published maps and institutional affiliations. 